\title{
Comparative effects of glibenclamide, metformin and insulin on fetal pancreatic histology and maternal blood glucose in pregnant streptozotocin-induced diabetic rats
}

\author{
Sodiq Kolawole Lawal ${ }^{1,6^{*}}$, Adeoluwa Akeem Adeniji ${ }^{2}$, Sheu Oluwadare Sulaiman ${ }^{3}$, \\ Mustapha Mas'ud Akajewole ${ }^{4}$, Muhammad Olanrewaju Buhari ${ }^{5}$, Abraham Adewale Osinubi ${ }^{2}$
}

1. Department of Anatomy, St. Francis University College of Health Sciences and Allied Sciences, Ifakara, Tanzania.

2. Department of Anatomy, College of Medicine, University of Lagos, Idi-Araba, Lagos, Nigeria.

3. Department of Physiology, Kampala International University Western campus, Ishaka-Bushenyi, Uganda.

4. Department of Human Anatomy, School of Health and Medical Sciences, State University of Zanzibar, Zanzibar, Tanzania

5. Department of Anatomy, Kampala International University Western campus, Ishaka-Bushenyi, Uganda.

6. Discipline of Clinical Anatomy, Nelson Mandela School of Medicine, University of KwaZulu-Natal, 4001, Durban, South Africa

\section{Email address of authors:}

Lawal Sodiq Kolawole: slawal@sfuchas.ac.tz; Adeniji Adeoluwa: godscrownbest@yahoo.com; Sulaiman Oluwadare Sheu: sheusulaiman@kiu.ac.ug; Mustapha Mas’ud Akajewole: Mustapha.masud@suza.ac.tz; Muhammad Olanrewaju Buhari: Muhammad.buhari@kiu. ac.ug; Osinubi Abraham Adewale: aaosinubi@cmul.edu.ng

\begin{abstract}
Background: Oral hypoglycemic agents use during pregnancy was assumed to cause fetal macrosomia and skeletal deformities, and maternal complications due to significant transfer across placenta or ineffective control of blood glucose.

Objective: This study investigated effects of insulin, metformin and glibenclamide on maternal blood glucose; and fetal crown-rump length, gross malformation and pancreatic histology in pregnant streptozotocin-induced diabetic rats.

Methods: Twenty-five pregnant rats of groups 1 to 5 as normal and diabetic controls; and diabetic treated with insulin, metformin and glibenclamide were used. Experimental GDM was induced using 45 and $35 \mathrm{mg} / \mathrm{Kgbw}$ of intraperitoneal streptozotocin.

Results: Metformin, Insulin and Glibenclamide significantly reduced maternal glucose by $140.6 \mathrm{mg} / \mathrm{dL}, 103.2 \mathrm{mg} / \mathrm{dL}$ and $98.54 \mathrm{mg} / \mathrm{dl}$; respectively and showed islets with regular interlobular ducts, islets with some irregular interlobular ducts, and islets with many irregular interlobular ducts in histological fetal pancreatic photomicrographs respectively. This depicts metformin having highest ameliorative effect. There were no significant differences in maternal and fetal body weights, maternal blood glucose between diabetic groups, and fetal gross examination.

Conclusion: At the doses used in this research, metformin and glibenclamide showed no adverse effects on maternal and fetal features in the treatment of GDM. Thus, they can be used as safe and inexpensive alternatives to insulin.

Keywords: Gestational diabetes mellitus, oral hypoglycemic agents, blood glucose, fetal malformation and fetal pancreatic histology.

DOI: https://dx.doi.org/10.4314/ahs.v19i3.25

Cite as: Lawal SK, Adeniji AA, Sulaiman SO, Akajewole MM, Bubari MO, Osinubi AA. Comparative effects of glibenclamide, metformin and insulin on fetal pancreatic histology and maternal blood glucose in pregnant streptozotocin-induced diabetic rats. Afri Health Sci. 2019;19(3): 2491-2504. bttps:// dx.doi.org/10.4314/abs.v19i3.25
\end{abstract}
Corresponding author:
Sodiq Kolawole Lawal,
Department of Anatomy,
St. Francis University College
of Health Sciences and Allied Sciences,
Ifakara, Tanzania.
Tel: +255785180163
Email:slawal@sfuchas.ac.tz

\section{Introduction}

Diabetes mellitus is a prevalent medical disorder in pregnancy and its incidence is increasing. Gestational diabetes mellitus (GDM) has been recognized for decades ${ }^{1}$. While its optimal monitoring and treatment has been controversial, it is apparent that even a mild degree of maternal hyperglycemia may result in fetal defects ${ }^{2,3}$.

During pregnancy, proper control of maternal blood glu-

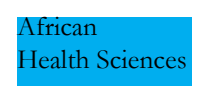

(C) 2019 Lawal et al. Licensee African Health Sciences. This is an Open Access article distributed under the terms of the Creative commons Attribution License (https://creativecommons.org/licenses/BY/4.0), which permits unrestricted use, distribution, and reproduction in any medium, provided the original work is properly cited.

African Health Sciences Vol 19 Issue 3, September, 2019 
cose level is important for the mother and the fetus ${ }^{4,5}$. This is because the maternal blood glucose level determines the fetal blood glucose level ${ }^{6}$ and the adverse consequences of GDM on the fetus and the mother increase linearly with increasing maternal glucose ${ }^{7}$. Thus, failure of proper control of maternal glucose level during pregnancy can increase the risk of teratogenicity, stillbirth and neonatal morbidity ${ }^{4}$.

The primary treatment of hyperglycemia or GDM during pregnancy is insulin after diet and physical exercise $e^{8,9,10,11}$. Although insulin has been shown not to cross the placenta to affect the fetuses directly ${ }^{6,12,13}$, it can lead to maternal hypoglycemia which can then lead to fetal defects ${ }^{14,15,16}$, depending on the dosage and period of exposure ${ }^{17}$.

Another common mode of treatment of GDM is the use of some common oral antidiabetic agents (ODAs) or oral hypoglycemic agents (OHA) but some of the commonly used OHAs have been contraindicated in pregnancy because they can cross the placenta into the fetal circulation and are believed to cause fetal defects ${ }^{18,19,20}$. Even though a lot of research, reviews and clinical trials have been carried out on the glibenclamide and metformin as commonly used $\mathrm{OHAs}{ }^{11}$, the evidence supporting their use in the treatment of GDM is still controversial.

While some researchers believed that there may be minimum placenta transfer of OHAs which could be teratogenic to the developing baby, some argued that OHAs may not be able to effectively reduce the blood glucose level thereby causing macrosomia and others reported that no serious safety concerns ${ }^{11}$. Therefore, this study was designed to compare the effect of insulin with that of glibenclamide and metformin in the treatment of GDM and the GDM's level of detriment to the fetuses.

\section{Materials and methods Experimental animal}

Thirty-five adult female and thirteen adult male Sprague-Dawley rats weighing between 120-160g and 300-350g respectively were procured from the Animal Laboratory of College of Medicine, University of Lagos. All the animals were housed in wire-mesh cages in the animal room of the Department of Anatomy, University of Lagos. The female rats were put in a cage partitioned into five compartments of the same size containing seven rats each. The bottom of the cage was made to allow passage of the rats' urine and fecal pellets into a removable tray put underneath it. The rats were allowed to acclimatize for three weeks. In addition, they were handled in accordance with the standard guide for the care and use of the animal laboratory, which was maintained at a temperature of $26-28^{\circ} \mathrm{C}$ and $12: 12$ light: dark cycle. The animals were fed with astandard diet of rat pellets and water was provided ad libitum.

\section{Determination of the oestrous cycle}

During the period of acclimatization, the phases of the oestrous cycle (proestrus, estrus, metestrus and diestrus) ${ }^{21}$ of the female rats were determined by daily examination of vaginal smear as described ${ }^{22,21}$. Briefly, $0.2 \mathrm{ml}$ of normal saline was drawn into a borosilicate glass medicine dropper and the tip of the dropper was carefully and gently inserted into the vaginal orifice of each rat at a depth of approximately $5 \mathrm{~mm}$. The saline was then flushed into the vagina from the dropper and immediately drawn back into $i^{21}$. The vaginal fluid from each rat was placed on a separate untreated glass microscopic slide and viewed while still wet under a light microscope at 100x magnification. The vaginal smears were taken once daily between 8 a.m and 10 a.m ${ }^{23}$ while holding each rat behind the shoulder blades in the supine position. The female rats with an oestrous cycle of 4 - 5 days were then selected for the study.

\section{Pregnancy}

Out of the 35 female rats, those with 4-5 day oestrous cycle were mated overnight with the male rats on the evening of the proestrus stage of their oestrous cycle and the mating was confirmed the following morning, denoted as day 0 of the pregnancy, by the presence of sperms in the vaginal smear ${ }^{24,25}$. Twenty-five pregnant rats randomly divided into five groups (containing five rats each) were used for the study.

\section{Induction of Experimental Gestational Diabetes Mellitus (GDM)}

The type 1 diabetic condition (Gestational Diabetes Mellitus) was induced in the groups 2 to 5 of the pregnant rats by intraperitoneal injection of double dosage of freshly prepared streptozotocin (STZ) (Sigma, St. Louis, MO, USA) in $0.1 \mathrm{M}$ sodium citrate buffer ( $\mathrm{pH} 4.5)$. The rats were fasted overnight from the night of day 0 of 
pregnancy and the initial dose of $45 \mathrm{mg} / \mathrm{Kg} \mathrm{b.w.}{ }^{26}$ was injected on day 1 of pregnancy. The rats were fasted overnight again from the night of day 1 and the second dose of $35 \mathrm{mg} / \mathrm{Kg}$ b.w. ${ }^{27,28}$ was injected on day 2. The use of the two doses was previously described and the group 1 rats (non-diabetic control) were injected an equal volume of citrate buffer only ${ }^{24,29}$. Fasting blood glucose level (diabetic status) was measured $48 \mathrm{~h}$ after STZ treatment (day 4 of pregnancy) using One Touch Ultra Mini Glucometer (Accu-chek, Roche, Germany) with a drop of blood obtained by tail vein puncture. The pregnant rats with fasting blood glucose value above $120 \mathrm{mg} / \mathrm{dL}$ were considered diabetic as recommended by $\mathrm{WHO}^{30}$.

\section{Drug treatment and grouping}

Drug treatment began after the pregnant rats have been confirmed diabetic on day 4 . The rats were either administered distilled water, insulin, or oral hypoglycemic agents (metformin and glibenclamide) once daily using oral cannula except for insulin, which was administered intraperitoneally. The animals were grouped and treated for 2 weeks (day 4 to day 17) as follows:

Group1: Non-diabetic control + distilled water $(0.5 \mathrm{ml})$

Group 2: Diabetic control + distilled water $(0.5 \mathrm{ml})$

Group 3: Diabetic + insulin (1 IU once daily)

Group 4: Diabetic + metformin $(36.43 \mathrm{mg} / \mathrm{kg}$ b.w $)$

Group 5: Diabetic + glibenclamide $(0.26 \mathrm{mg} / \mathrm{kg}$ b.w $)$

\section{Maternal body weights and fasting blood glucose}

All the rats were weighed and their fasting blood glucose was taken before STZ administration, before the commencement of drug administrations on day 4 of the pregnancy, after 1 week (day 11) and after 2 weeks of the treatment just before sacrifice (day 18). On day 4, the diabetic rats were grouped in such a way that the rats with higher glucose levels were randomly assigned to the insulin, metformin and glibenclamide treated groups while those with lower glucose levels were put in the diabetic untreated group. This regrouping is important to prevent the death of the diabetic untreated rats before the end of the experiment since the highly diabetic rats rarely survive for a longer period of time without treatment ${ }^{77}$. Also, putting the highly diabetic rats in drug-treated groups will enhance the effect of insulin ${ }^{78}$ and probably the OHAs.

\section{Sacrifice and sample collection}

A day after the completion of the treatment (day 18), the rats were weighed and their fasting blood glucose was taken. Then, they were anaesthetized with diethyl ether (TKM PharmaPvt, Ltd., Andhra Pradesh, India). After becoming unconscious, the blood was collected from each of the rats into separate plain tubes followed by dissection of each of them. After being dissected, the fetuses were removed. Each of the fetuses was examined for any morphological deformity and later dissected and its pancreas excised.

\section{Fetal examination}

The fetuses were examined for gross deformity using a hand lens. Then, their average number, weight and crownrump length were determined for each group.

\section{Histology of the fetal pancreas}

The pancreas excised from each fetus was rinsed in icecold $1.15 \% \mathrm{KCl}$, blotted and weighed for sub-Cellular fraction preparation. A section of the pancreas was cut and introduced into $10 \%$ formaldehyde (formalin) solution to preserve the tissues for histopathology.

\section{Hematoxylin and Eosin (H \& E) Staining of the pancreatic tissue for histological studies}

The tissue samples in 10\% buffered formalin were sliced to approximately $1 \mathrm{~cm}$ thick and placed into the cassettes. Then, the cassettes were placed in a tissue automatic processor machine, in which dehydration was done with graded alcohol $(70 \%, 90 \%$ and $100 \%)$, clearing was done with xylene in order to remove fat from tissues and increase the refractive index, the infiltration was carried out with paraffin wax at about $60^{\circ} \mathrm{C}$, and finally embedding and blocking process was done. The whole procedure was done automatically by the processor machine overnight for about (14 h). Each block was trimmed and then sectioned about $3 \mu \mathrm{m}$ by using a microtome. Then, Hematoxylin and eosin ( $\mathrm{H} \& \mathrm{E}$ ) staining procedure was done as follows: the sectioned tissues were deparaffinized by placing the slide on the burner with regulated temperature and placed in the xylene. This was followed by hydration where the tissue sections passed through decreasing concentration of alcohol baths and water $(100 \%, 90 \%$, $80 \%, 70 \%$ ). The first staining was done with hematoxylin for 3-5 minutes and then washed in running tap water until sections "blue" for 5 minutes or less, it was then differentiated in $1 \%$ acid alcohol $(1 \% \mathrm{HCl}$ in $70 \%$ alcohol) for 5 minutes. Washing was done in running tap water 
until the sections were again blue by dipping in an alkaline solution (e.g. ammonia water) followed by tap water wash. The second stain was done in $1 \%$ Eosin $Y$ for 0 minutes, washed in tap water for 1-5 minutes, dehydrated in increasing concentration of alcohols and cleared in xylene. The prepared slides were mounted in DPX for microscopic observations.

\section{Statistical analysis}

All the quantitative results were presented in a tabular form as mean \pm Standard Error of Mean (SEM). The maternal body weight and blood glucose levels were analyzed with GraphPad Prism version 7 (GraphPad Software Inc., CA. USA)using repeated measures ANOVA while the fetal parameters were analyzed using One-way ANOVA. Multiple comparisons were done using Tukey's test. A p-value of $\mathrm{p}<0.05$ was considered to be statistically significant.

\section{Results}

Effect of induced GDM and drug treatment on maternal

\section{Table 1: Maternal blood glucose in $\mathrm{mg} / \mathrm{dL}$ and its reduction (in bracket) due to the administration of hypoglycemic agents at different days of pregnancy}

\begin{tabular}{|l|l|l|l|l|l}
\hline Days of pregnancy & $\begin{array}{l}\text { Normal } \\
\text { Control }\end{array}$ & $\begin{array}{l}\text { Diabetic } \\
\text { Control }\end{array}$ & $\begin{array}{l}\text { Diabetic }+ \\
\text { Insulin }\end{array}$ & $\begin{array}{l}\text { Diabetic }+ \\
\text { Metformin }\end{array}$ & $\begin{array}{l}\text { Diabetic }+ \\
\text { Glibenclamide }\end{array}$ \\
\hline $\begin{array}{l}\text { Baseline (Before } \\
\text { STZ) }\end{array}$ & $\begin{array}{l}91.6 \pm \\
1.7\end{array}$ & $93.8 \pm 3.1$ & $91.8 \pm 3.8$ & $91.4 \pm 3.7$ & $95.2 \pm 1.6$ \\
\hline $\begin{array}{l}\text { Day 4 (just before } \\
\text { beginning the drug } \\
\text { treatment) }\end{array}$ & $91.2 \pm 1.6$ & $164 \pm 13.4^{\mathrm{a}}$ & $237.2 \pm 18.6^{\mathrm{a}, \mathrm{b}}$ & $280.6 \pm 51.1^{\mathrm{a}, \mathrm{b}}$ & $216.8 \pm 38.9^{\mathrm{a}}$ \\
\hline Day 11 of pregnancy & $\begin{array}{l}82.4 \pm \\
5.1\end{array}$ & $\begin{array}{l}152.8 \pm \\
8.6^{\mathrm{a}}\end{array}$ & $\begin{array}{l}183.4 \pm 12.3^{\mathrm{a}} \\
(53.8 \mathrm{mg} / \mathrm{dL}, \\
22.7 \%)\end{array}$ & $\begin{array}{l}190.8 \pm 24.1^{\mathrm{a}, \mathrm{c}} \\
(89.8 \mathrm{mg} / \mathrm{dL},\end{array}$ & $\begin{array}{l}151.2 \pm 22.1^{\mathrm{c}} \\
(65.6 \mathrm{mg} / \mathrm{dL}, \\
30.3 \%)^{\mathrm{c}}\end{array}$ \\
\hline Day 18 of pregnancy & $89.8 \pm 3.9$ & $\begin{array}{l}141.2 \pm \\
9.0\end{array}$ & $\begin{array}{l}134 \pm 11.2^{\mathrm{c}} \\
(103.2 \\
\mathrm{mg} / \mathrm{dL}, 43.5 \%)^{\mathrm{c}}\end{array}$ & $\begin{array}{l}140 \pm 7.6^{\mathrm{c}} \\
(140.6 \\
\left.\mathrm{mg} / \mathrm{dL}, 50.2^{\mathrm{c}} \%\right)^{\mathrm{c}}\end{array}$ & $\begin{array}{l}118.26 \pm 7.0^{\mathrm{c}} \\
(98.54 \\
\left.\mathrm{mg} / \mathrm{dL}, 45.5^{\circ} /\right)^{\mathrm{c}}\end{array}$ \\
\hline
\end{tabular}

Values are presented as mean $( \pm$ SEM $)$ and are significant at $\mathrm{p}<0.05$. $\mathrm{N}=5$.

${ }^{a}$ Significant compared with the normal control. ${ }^{b}$ Significant compared with diabetic control

${ }^{\mathrm{c}}$ Significant compared to day 4 for each of the treated groups.

\section{blood glucose: Table 1}

\section{Effect of GDM}

There was no observed significant difference in the blood glucose levels within the normal control group and within the diabetic control group throughout the days of the experiment. The GDM significantly increased blood glucose levels of all the diabetic rats on day 4 of pregnancy compared to the normal control. Accordingly, all the drug-treated rats showed a rise in glucose levels which were significant in both the insulin-treated $(\mathrm{p}=0.0372)$ and metformin-treated $(\mathrm{p}=0.0001)$ rats on day 4 of pregnancy compared with diabetic control.

\section{Effect of insulin}

Insulin reduced blood glucose by the mean values of 53.8 $\mathrm{mg} / \mathrm{dL}(22.7 \%)$ and $103.2 \mathrm{mg} / \mathrm{dL}(43.5 \%)$ on the days 11 and 18 respectively but the reductions were only significant on day 18 ( $\mathrm{p}<0.0001)$ compared with day 4 .

\section{Effect of metformin}

When compared with day 4, metformin significantly reduced blood glucose level by a mean value of $89.8 \mathrm{mg} /$ $\mathrm{dL}(32 \%)$ on day $11(\mathrm{p}=0.0003)$ and by the mean value of $140.6 \mathrm{mg} / \mathrm{dL}(50.2 \%)$ on day $18(\mathrm{p}<0.0001)$.

\section{Effect of glibenclamide}

When compared with day 4, glibenclamide significantly reduced blood glucose level by a mean value of $65.6 \mathrm{mg} /$ $\mathrm{dL}(30.3 \%)$ on day $11(\mathrm{p}=0.0129)$ and by the mean value 
of $98.54 \mathrm{mg} / \mathrm{dL}(45.5 \%)$ on day $18(\mathrm{p}<0.0001)$.

NOTE: Each of the drugs caused further reduction of the blood glucose between days 11 and 18 but the reductions were not significant for all of them. Also, there was no significant difference in the maternal blood glucose levels between all the diabetic (treated and untreated) groups at the end of the experiment.

Effect of induced GDM and drug treatment on maternal

Table 2: Maternal body weight (g) across all the groups at different days of pregnancy

\begin{tabular}{|l|l|l|l|l|l}
\hline Days of pregnancy & $\begin{array}{l}\text { Normal } \\
\text { Control }\end{array}$ & $\begin{array}{l}\text { Diabetic } \\
\text { Control }\end{array}$ & $\begin{array}{l}\text { Diabetic }+ \\
\text { Insulin }\end{array}$ & $\begin{array}{l}\text { Diabetic }+ \\
\text { Metformin }\end{array}$ & $\begin{array}{l}\text { Diabetic }+ \\
\text { Glibenclamide }\end{array}$ \\
\hline Baseline (before STZ) & $127.2 \pm 9.7$ & $130 \pm 8.1$ & $125.36 \pm 7.1$ & $126.32 \pm 10.7$ & $133.32 \pm 10.7$ \\
\hline $\begin{array}{l}\text { Day 4 of pregnancy } \\
\text { (beginning of drug } \\
\text { treatment) }\end{array}$ & $136.2 \pm 11.2$ & $136.04 \pm 6.9$ & $120.24 \pm 6.1$ & $116.62 \pm 10.0$ & $126.08 \pm 10.0$ \\
\hline Day 11 of pregnancy & $154.64 \pm 12.5$ & $138.58 \pm 5.7$ & $120.18 \pm 6.9$ & $119.92 \pm 13.9$ & $125.66 \pm 8.6$ \\
\hline Day 18 of pregnancy & $149.7 \pm 13.4$ & $127 \pm 9.5$ & $129 \pm 6.1$ & $123.12 \pm 15.9$ & $145.08 \pm 7.6^{\text {c,d }}$ \\
\hline
\end{tabular}

Values are presented as mean $( \pm \mathrm{SEM})$ and are significant at $\mathrm{p}<0.05$. $\mathrm{N}=5$.

${ }^{\mathrm{c}}$ Significant compared to day 4 for each of the treated groups.

${ }^{\mathrm{d}}$ Significant compared to day 11 for each of the treated groups.

body weight: Table 2

There was no significant weight difference between all the groups and within the groups throughout the treatment days except in the glibenclamide group. In the glibenclamide group, there was a significant weight increase on day 18 compared with day $4(p=0.0216)$ and day 11 $(\mathrm{p}=0.0181)$.

Physical examination of fetal parameters: Table 3 There was no significant difference in the examined physical parameters of the fetuses across all the groups including the control group.

\section{Table 3: Average fetal physical parameters - average number, body weight (g) and Crown- rump length $(\mathrm{cm})$ across all the groups}

\begin{tabular}{|l|c|c|l|}
\hline Groups & Body Weight (g) & Crown-rump length (cm) & No. of Pups \\
\hline Normal Control & $6 \pm 0.32$ & $2.2 \pm 0.07$ & $6 \pm 0.45$ \\
\hline Diabetic Control & $6.2 \pm 0.37$ & $2.1 \pm 0.13$ & $5.8 \pm 0.37$ \\
\hline Diabetic + Insulin & $6.4 \pm 0.4$ & $2.08+0.04$ & $5.8 \pm 0.37$ \\
\hline Diabetic + Metformin & $6.4 \pm 0.25$ & $2.02 \pm 0.07$ & $6.2 \pm 0.37$ \\
\hline Diabetic + Glibenclamide & $6.4 \pm 0.4$ & $2.12 \pm 0.05$ & $5.8 \pm 0.2$ \\
\hline
\end{tabular}

\section{Discussion}

This research was designed to compare the safety and effectiveness of insulin and two commonly used oral hypoglycemic agents/ oral antidiabetic agents (metformin and glibenclamide $)^{11}$ in the treatment of gestational diabetes mellitus and its complications in both the mother and the fetus using streptozotocin (STZ) - induced diabetic pregnant rats. Diabetes in pregnancy is associated with serious complications for both the mother and the fetus, and the adverse consequences on the fetus and the mother increase linearly with increasing maternal blood glucose ${ }^{7}$. Some of the fetal risks are spontaneous abortion, intrauterine death, stillbirth, congenital malformation, shoulder dystocia and birth injuries, neonatal hypoglycemia and infant respiratory distress syndrome (RDS) while maternal risks include hydramnios, hypertension and preeclampsia, prolonged labour, obstructed labour, 
infections, assisted delivery, uterine atonia and postpartum hemorrhage ${ }^{31}$. Thus, good maternal blood glucose control before conception and throughout pregnancy reduces the risks substantially ${ }^{32,33}$. Therefore, management of maternal GDM is one of the priorities of $\mathrm{WHO}^{31}$ because its incidence is increasing ${ }^{34}$.

After diet control and physical exercise in the treatment of GDM, insulin remains the gold standard ${ }^{10}$. Taking insulin as the gold standard was based on unparalleled efficacy standard and because of lack of any well-studied alternative ${ }^{11}$. However, disadvantages of insulin use such as multiple daily injection sites, maternal weight gain, the risk of hypoglycemia, high cost and handling have led to consideration of oral hypoglycemic agents (OHA) especially, metformin and glibenclamide, as preferred alternatives?. The use of OHAs raised a concern about the risks of fetal teratogenicity and neonatal hypoglycemia as a result of their 10-16\% maternal to fetal transfer rate $^{8,35}$. Therefore, this research was carried out to compare the effects of insulin, metformin and glibenclamide in STZ-induced diabetic pregnant rats. The effect of the drugs on maternal blood glucose and body weight, as well as fetal malformation and fetal pancreas, was considered.

\section{Maternal blood glucose and body weight}

On day 4, the diabetic rats were grouped in such a way that the rats with higher glucose levels were randomly assigned to the insulin, metformin and glibenclamide treated groups while those with lower glucose levels were put in the diabetic untreated group. This regrouping is important to prevent the death of the diabetic untreated rats before the end of the experiment since the highly diabetic rats rarely survive for a longer period of time without treatment ${ }^{78}$, and it will enhance the effect of insulin ${ }^{78}$ and probably the OHAs. At the end of the research (day 18), all the drugs reduced maternal blood glucose by 140.6 $\mathrm{mg} / \mathrm{dL}(50.2 \%)$, and $103.2 \mathrm{mg} / \mathrm{dL}(43.5 \%)$ and 98.54 $\mathrm{mg} / \mathrm{dL}(45.5 \%)$ for metformin, insulin and glibenclamide respectively (table 1 ). The blood glucose reductions occurred without the risk of hypoglycemia (blood glucose $<3.9 \mathrm{mmol} / \mathrm{L}$ or $70 \mathrm{mg} / \mathrm{dL}$ ) at the drug doses used in this research and this is in agreement with the previous report $^{71}$. Since the management of GDM is primarily aimed at the glycemic target to reduce the incidence of fetal and maternal complications ${ }^{8,36}$, metformin and glibenclamide can be used as safe alternatives to insulin. This is supported by the fact that there was no significant difference in the blood glucose levels between all the treated groups at the end of this research and it corroborates with the previous reports from the review of randomized controlled trials which showed that there was no significant difference in maternal fasting glucose between glyburide (glibenclamide) and insulin although there was slightly lower fasting blood glucose in the insulin group than in glyburide group ${ }^{37}$, and between OHAs and insulin ${ }^{8}$. It was even showed that maternal complications were higher in insulin-treated GDM women compared to metformin and glibenclamide ${ }^{8}$. More reduction in fasting blood glucose observed in the metformin-treated group than the glibenclamide treated group is supported by the report of Mansour and colleagues ${ }^{59}$, who also reported higher and significant reductions in fasting blood glucose and glycosylated haemoglobin (HbA1c) in metformin-treated rats than in glibenclamide-treated rats. In addition, Atsuo et al. reported that insulin, glibenclamide and metformin caused significantly improved glucose tolerance in mildly diabetic rats while only insulin and metformin but not glibenclamide significantly improved glucose tolerance in severely diabetic rats ${ }^{60}$.

Although there was no significant maternal weight difference across all the groups, the glibenclamide-treated group showed a significant weight increase at the end of the research compared to the previous days (table 2). This is supported by the previous report that oral anti-diabetic drugs like sulfonylurea including glibenclamide, glinides, and glitazones as well as insulin increase body weight within years by up to $8 \mathrm{~kg}$ while metformin decreases it $^{58}$ and this may be a call for careful monitoring of glibenclamide use in GDM.

\section{Fetal gross/physical examination}

The results obtained from the fetal gross examinations showed that there were no statistically significant differences in body weight, crown-rump length and number of fetal across all groups (treated and control) (table 3). This result is in line with the previous reports concerning the use of oral hypoglycemic agents during pregnancy. According to Tran et al. ${ }^{18}$, the risk of embryo-fetal harm with biguanides appears to be very low or non-existent. Also, the birth defect in newborns of mothers who had used one of the oral hypoglycemic agents was thought to be the result of uncontrolled diabetes but not to the drugs taken ${ }^{12}$. In addition, it was reported that metformin did not result in major malformation or significant changes in mouse embryonic growth ${ }^{67}$ and that metformin also protected neural cells against apoptosis and neural de-

African Health Sciences Vol 19 Issue 3, September, 2019 


\section{Table 3: Average fetal physical parameters - average number, body weight (g) and Crown- rump length $(\mathrm{cm})$ across all the groups}

\begin{tabular}{|l|c|c|l|}
\hline Groups & Body Weight (g) & Crown-rump length (cm) & No. of Pups \\
\hline Normal Control & $6 \pm 0.32$ & $2.2 \pm 0.07$ & $6 \pm 0.45$ \\
\hline Diabetic Control & $6.2 \pm 0.37$ & $2.1 \pm 0.13$ & $5.8 \pm 0.37$ \\
\hline Diabetic + Insulin & $6.4 \pm 0.4$ & $2.08+0.04$ & $5.8 \pm 0.37$ \\
\hline Diabetic + Metformin & $6.4 \pm 0.25$ & $2.02 \pm 0.07$ & $6.2 \pm 0.37$ \\
\hline Diabetic + Glibenclamide & $6.4 \pm 0.4$ & $2.12 \pm 0.05$ & $5.8 \pm 0.2$ \\
\hline
\end{tabular}

fects caused by high glucose challenge in rats $^{68}$ and mice ${ }^{69}$. Fetal pancreas

In the control (non-diabetic) group, the pancreatic histology showed an intact fetal pancreatic $\beta$ and acini cells with regular interlobular ducts (Figure 1). Group 2 (diabetic without treatment) pancreas showed large irregularly shaped degenerating Islets of Langerhans with irregular interlobular ducts (Figure 2). Diabetes mediated hyperglycemia has been shown to generate a high level of reactive oxygen species (ROS) from cells causing oxidative stress ${ }^{38,39,40}$. Exposure to chronic oxidative stress destroys body cells. $\beta$ cells are especially vulnerable to attacks by ROS because expression of antioxidant enzymes in pancreatic islets is low ${ }^{41,42}$ and $\beta$ cells have a high oxidative energy requirement. Hyperglycemia and increased ROS impair glucose-stimulated insulin secretion ${ }^{43,44}$, decrease expression of key $\beta$ cell genes ${ }^{45-49}$ and induce cell death $^{50,51}$, worsening the diabetic condition related com-

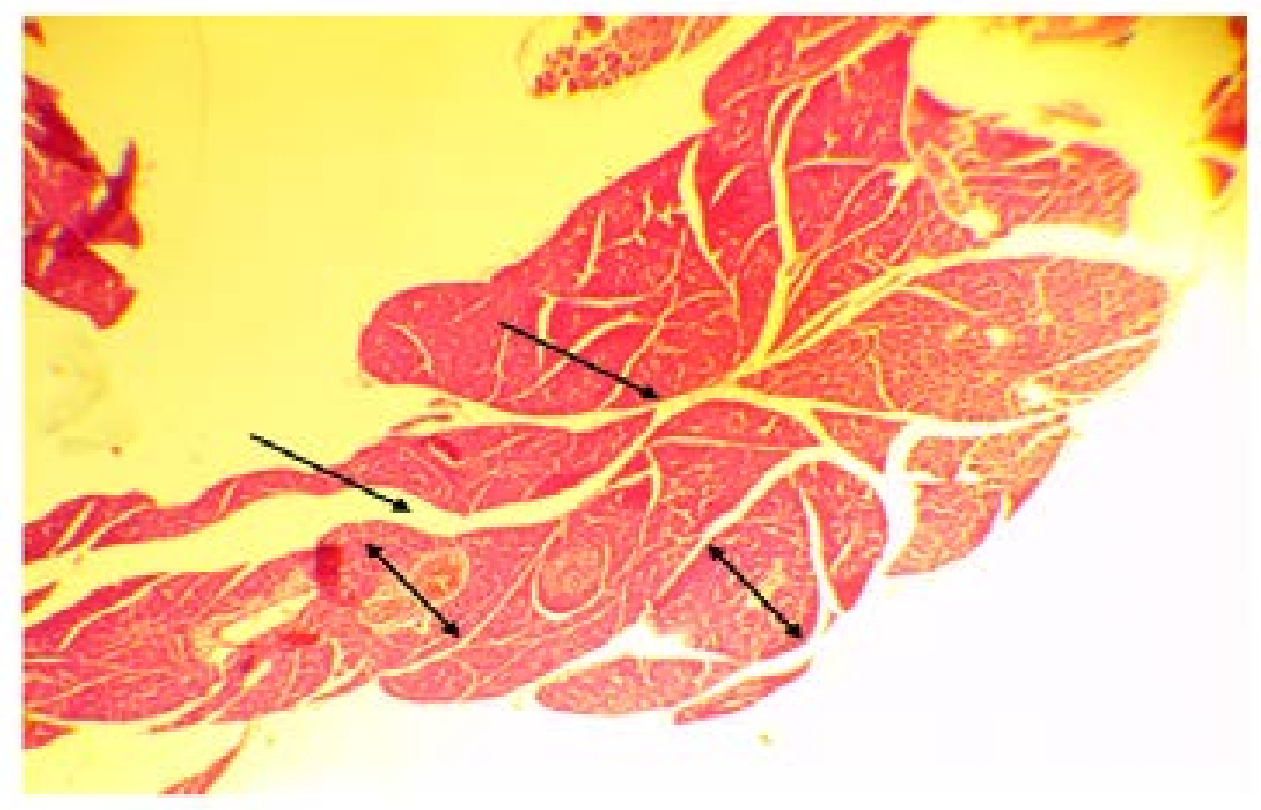

Figure 1: Photomicrograph of the non-diabetic control (group 1) fetal pancreas using H\&E (x100), showing normal distribution of islets of Langerhans $(\leftrightarrow)$ with well-developed interlobular ducts ( $\rightarrow$ ) interspersed among the pancreatic lobules. 
plications.

Since maternal blood glucose level determines fetal blood glucose level ${ }^{6}$ and because adverse consequence of increased maternal blood glucose on the fetus and the mother increases linearly with maternal glucose ${ }^{7}$, degenerating Islets of Langerhans in fetal pancreas of this diabetic group can be linked to maternal hyperglycemia which in turn resulted in high ROS generation in the fetal pancreatic cells leading to subsequent fetal islet of Lang-

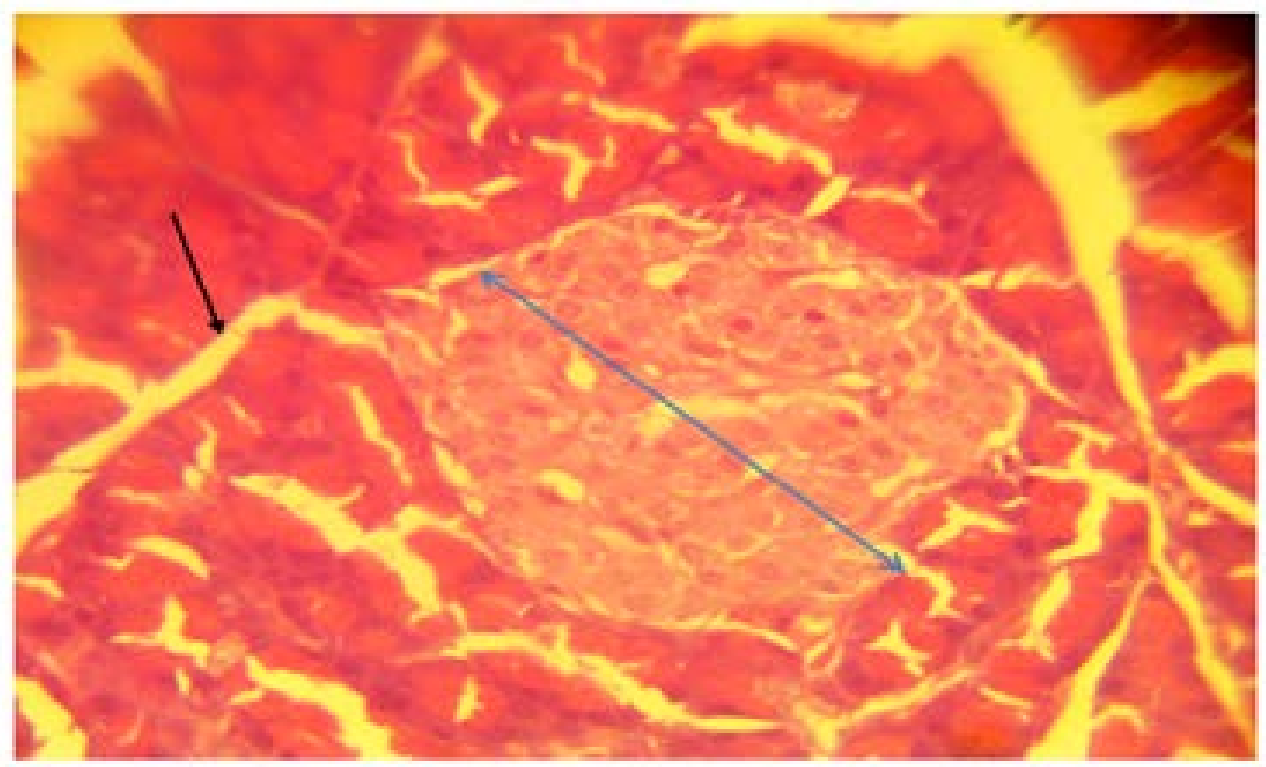

Figure 2: Photomicrograph of the diabetic control (group 2) fetal pancreas using H\&E (x100), showing a large irregularly shaped degenerating islets of Langerhans $(\leftrightarrow)$ with irregular interlobular ducts $(\rightarrow)$.

erhans degeneration (Figure 2).

Figure 3 showed developing fetal pancreatic Islets of Langerhans with some irregular interlobular ducts fol- lowing treatment with insulin. This might result from the ability of insulin treatment to rescue $\beta$ cells and facilitate their recovery from hyperglycemia-induced destruction due to the insulin's effects as anti-hyperglycemic, anti-in-

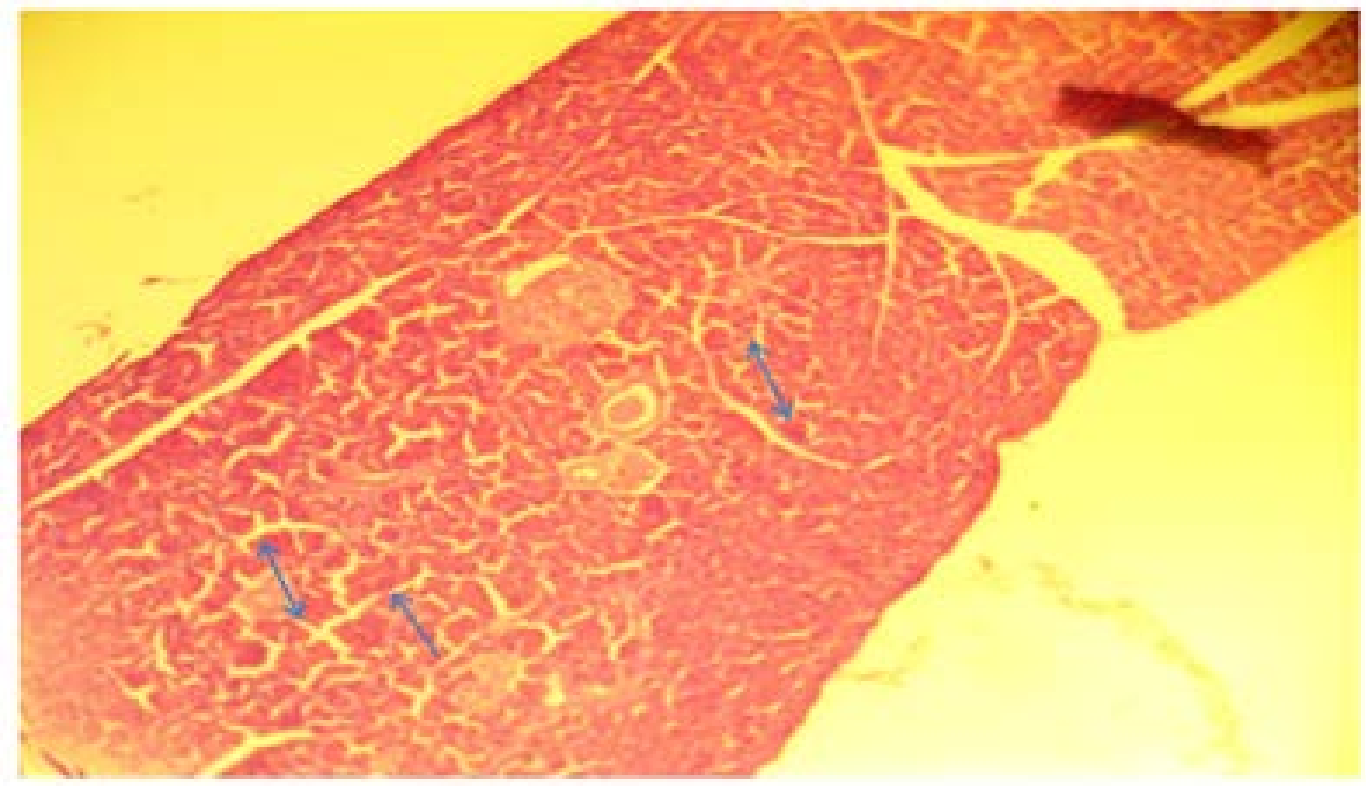

Figure 3: Photomicrograph of the diabetic + insulin (group 3 ) fetal pancreas using H\&E (x 100), showing normal developing islets of Langerhans $(\leftrightarrow)$ ) and some irregular interlobular ducts. 
flammatory and anti-oxidant agents ${ }^{52}$.

In figure 4, the fetal pancreatic histology showed the well-rounded distribution of Islets of Langerhans with regular interlobular ducts implying that the pancreatic recovery was more than that of insulin. In a recent meta-analysis, metformin performed well compared to insulin as it was associated with significantly less maternal weight gain, a trend towards a lower rate of any neonatal hypoglycemia,less pregnancy-induced hypertension and less severe neonatal hypoglycemia ${ }^{53}$. This might be due to the higher antihyperglycemic effect of metformin more than that of insulin (table 1) and its higher weight reduction effect (table 2) as well as its higher antioxidant effect. Although it was previously reported that metformin impaired insulin secretion in primary human and mouse islets, and in rat pancreatic beta cell lines in a normoglycemic environment ${ }^{61,62}$, it has been reported that metformin enhanced mouse pancreatic progenitor cells ${ }^{63}$ and protected mouse pancreatic beta cells exposed to fatty-acid induced stress ${ }^{64}$ and high glucose ${ }^{65}$. Therefore, metformin overuse without metabolic challenge could cause beta cell toxicity ${ }^{66}$ but in a hyperglycemic environment, as in this

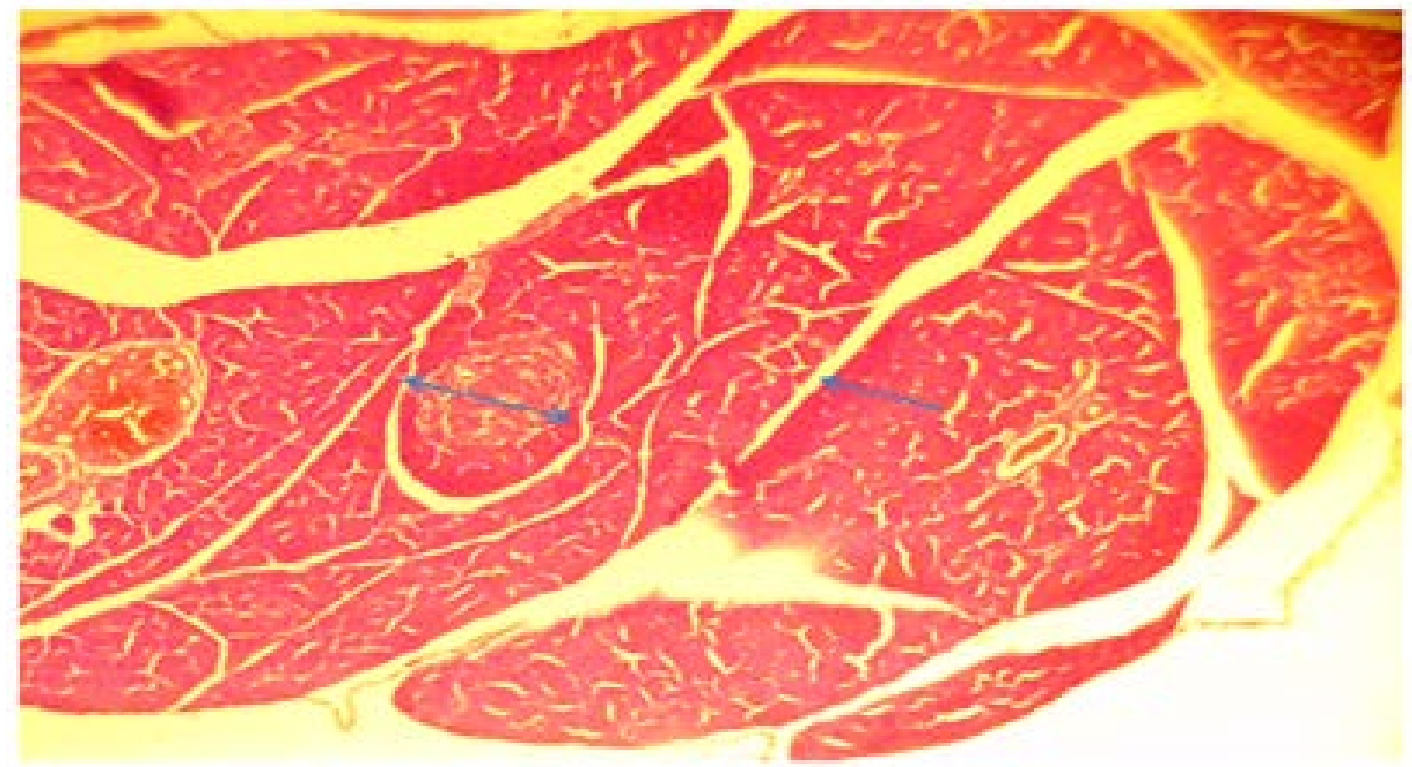

Figure 4: Photomicrograph of the diabetic + metformin (group 4) fetal pancreas using H\&E (x100), showing the well-rounded distribution of islets Langerhans $(\leftrightarrow)$ ) with regular interlobular ducts $(\rightarrow$ ) within the developed pancreatic cells.

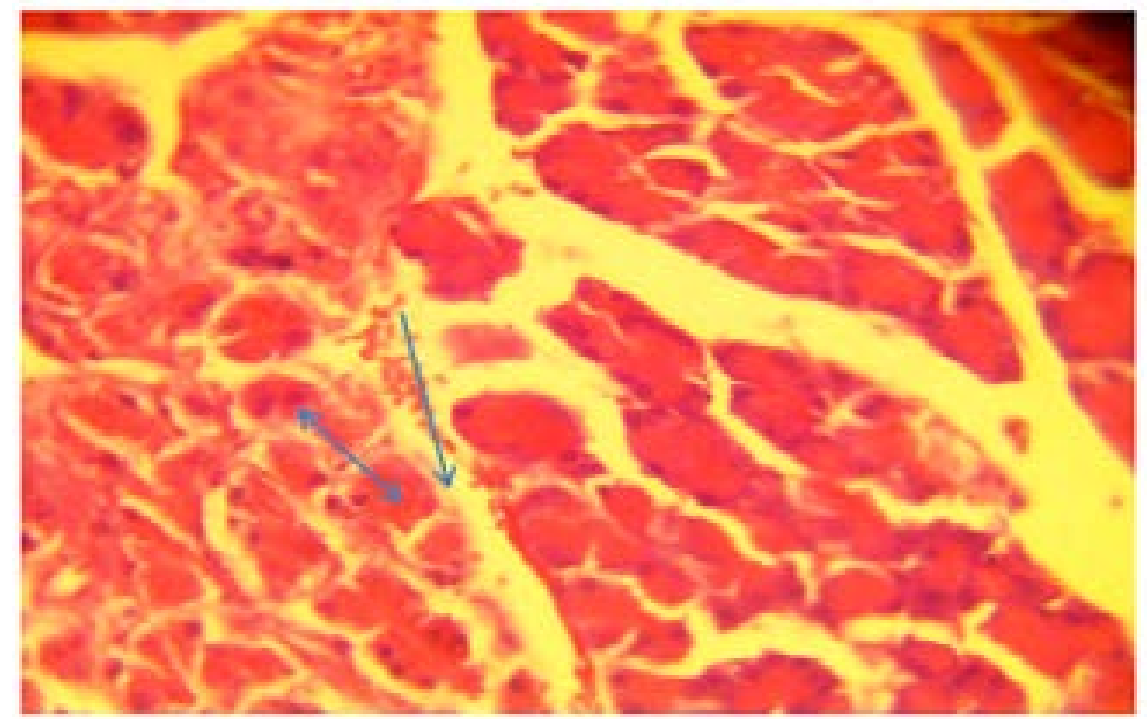

Figure 5: Photomicrograph of the diabetic + glibenclamide (group 5) fetal pancreas using H\&E (x100), numerous developing islets Langerhans $(\leftrightarrow)$ with irregular interlobular ducts $(\rightarrow)$ slightly less developed than that of the insulin group within the developing pancreatic cells 
research, metformin is protective to the pancreas.

Figure 5 showed numerous developing Islet cells with many irregular interlobular ducts following treatment with glibenclamide. The level of Islets' development was less than those of insulin and metformin (Figure 5). This can be due to the relatively lower ability of glibenclamide to reduce maternal blood glucose and body weight compared to metformin and insulin (tables $1 \& 2$ ). The poorpancreatic recovery with the glibenclamide treatment could also be due to its lower antioxidant effect as previously reported ${ }^{54,55}$.

The results of this research show that metformin and glibenclamide are safe alternatives to insulin in GDM at the doses used. Although head-to-head comparison of insulin and OHA use in pregnancy is still scanty in animal research, there are reviews, meta-analyses and randomized clinical trials ${ }^{37,8,71,72,73,74}$ whose authors reported metformin and glibenclamide as being safe and effective alternatives to insulin in the treatment of GDM with minimal or no complications in both the fetus and mothers. Direct comparison of metformin and glibenclamide showed higher glycemic control by metformin than glibenclamide ${ }^{75,57}$. Improved type 2 diabetes mellitus condition using combined insulin and metformin has been reported ${ }^{56}$ while combining insulin with metformin treatment, to improve glycaemic control towards the end of the pregnancy, showed more favourable results than insulin alone $e^{57,76}$. In addition, the rate of severe hypoglycemia and weight gain was reported to be reduced in metformin-treated GDM patients than insulin-treated patients ${ }^{77,78}$.

However, this research adds that metformin is more effective than both the glibenclamide and insulin in the treatment of GDM with no risk of hypoglycemia and fetal malformation, as well as in the improvement of fetal and maternal outcomes at the doses used. The use of metformin and glibenclamide as safe and inexpensive alternatives to insulin is especially favoured by the fact that no significant difference was observed between all the groups treated with each of the drugs in all the measured maternal and parameters at the dosage used in this research. Nevertheless, more research is still needed in testing these drugs on more fetal parameters and in comparing the antioxidant effects of metformin and glibenclamide with insulin in GDM patients or in laboratory animals.

\section{Conclusion}

At the doses used in this research, metformin and glibenclamide use in the treatment of gestational diabetes mellitus showed no adverse effects on maternal and fetal features. Metformin had the highest effect in ameliorating the adverse effects of gestational diabetes than insulin and glibenclamide without causing hypoglycemia.

\section{Acknowledgement}

The authors acknowledge IBRO Writing Paper Workshop (2017) committees for their mentorship and handson practical sessions on paper writing.

The authors also acknowledge the staff members of the Histology Laboratory, University of Lagos College of Medicine.

\section{Conflict of interest}

There is no conflict of interest to declare.

\section{References}

1. Freinkel N, Josimovich J. Conference planning committee: American Diabetes Association Workshop Conference on Gestational Diabetes. Diabetes Care. 1980; 3:499-501. PubMed

2. Kjos SL, Buchanan TA. Gestational diabetes mellitus. N Engl J Med. 1999; 341:1749-1756. PubMed

3. Correa A, Suzanne M, Gilboa LM. Besser LD, Botto CA, Moore CA, Hobbs MA, Cleves TJ, Riehle-Colarusso D, Kim W and Albert R. Diabetes mellitus and birth defects. Am J Obstet Gynecol. 2008; 199(3): 237. PubMed .e1-237.e9. doi: 10.1016/j.ajog.2008.06.028

4. Greuter MJ, van Emmerik NM, Wouters MG, van Tulder MW. Quality of guidelines on the management of diabetes in pregnancy: a systematic review. BMC pregnancy and childbirth. 2012; 12:58.

5. Lapolla A, Dalfra MG, Fedele D. Insulin therapy in pregnancy complicated by diabetes: are insulin analogs a new tool? Diabetes/metabolism research and reviews. 2005;21: 241-52.

6. Trujillo AL. Insulin Analogs and Pregnancy. Diabetes Spectrum. 2007; 20:94-101. PubMed

7. Metzger BE, Lowe LP, Dyer AR, Trimble ER, Chaovarindr U, Coustan DR, et al. Hyperglycemia and adverse pregnancy outcomes. N Engl J Med. 2008;358(19):1991 -2002. PubMed

8. Dhulkotia JS, Ola B, Fraser R, Tom F et al. Oral hypoglycemic agents vs insulin in management of gestational 
diabetes: a systematic review and metaanalysis. $A m \mathrm{~J} \mathrm{Ob-}$ stet Gynecol. 2010; 203:457. e1-9. PubMed

9. Bertini, AM, Silva, JC, Taborda, W, Becker F, Bebber FRL, Viesi JMZ, Aquim, G. and Ribeiro, T.E. Perinatal Outcomes and the Use of Oral Hypoglycaemic Agents. Journal of Perinatal Medicine. 2005; 33 :519-523. http://dx. doi.org/10.1515/JPM.2005.092

10. Blumer I, Hadar E, Hadden DR, Jovanovič L, Mestman JH, Murad MH, et al. Diabetes and pregnancy: An endocrine society clinical practice guideline. J Clin Endocrinol Metab. 2013; 98:4227-49.

11. Kalra B, Gupta Y, Singla R, Kalra S. Use of oral anti-diabetic agents in pregnancy: A pragmatic approach. North Am J Med Sci. 2015; 7:6-12. PubMed

12. Garcia-Bournissen F, Feig DS, Koren G. Maternal-fetal transport of hypoglycaemic drugs. Clinical pharmacokinetics. 2003; 42:303-13.

13. Poon K, King AB. Glargine D. Safety and efficacy profiles of the long-acting basal insulin analogs. Drug, healthcare and patient safety. 2010; 2:213-23.

14. de Valk HW, Visser GH. Insulin during pregnancy, labour and delivery. Best practice \& research Clinical obstetrics \& gynaecology. 2011; 25:65-76. PubMed

15. Eriksson UJ. Congenital malformations in diabetic animal models--a review. Diabetes Res. 1984; 1:57-66. PubMed

16. Landauer W. Is Insulin a teratogen? Teratology. 1972; 5:129-35. PubMed

17. Kuwata C, Saeki N, Honda K, Matsuoka T, Tsuchiya Y, Shimomura K. Effects of Maternal Hypoglycemia on Fetal Eye and Skeleton Development in Rats. Reproductive Toxicology, 2017, http://dx.doi.org/10.1016/j.reprotox.2017.05.009

18. Tran ND, Hunter SK, Yankowitz J. Oral hypoglycemic agents in pregnancy. Obstetrical \& gynecological survey. 2004;59: 456-63; quiz 85. PubMed

19. Miyamoto M, Sakaguchi T, Midorikawa O. Teratogenic Effects of Sulfonylureas and Insulin in Rats. Congenital Anomalies. 1977; 17:31-7

20. Truchmann-Duplessis HM-P. Oral antidiabetic drugs and teratogenicity. Lancet. 1963;2.

21. Byers SL, Wiles MV, Dunn SL, Taft RA. Mouse Estrous Cycle Identification Tool and Images. PLoS One. 2012; 7(4): PubMed e35538. doi:10.1371/journal. pone. 0035538

22. Cora MC, Linda K, and Greg T. Vaginal Cytology of the Laboratory Rat and Mouse: Review and Criteria for the Staging of the Estrous Cycle Using Stained Vaginal
Smears. Toxicologic Pathology. 2015. 43: 776-793. Copyright \# 2015 by The Author(s) ISSN: 0192-6233 print / 15331601 online DOI: 10.1177/0192623315570339

23. Gbotolorun SC, Oremosu AA, Osinubi AAA, Noronha CC, Coker HAB, Silva BO Amodiaquine hydrochloride (AQ.HCl) on the reproductive function of the adult cyclic Sprague-Dawley (S-D) rats. Biology and Medicine. 2012:4 (3): 141-146.

24. Siti HA, Cini MJ, Nur ISM, Massita N, Rajesh R, Aishah A, and FazlinMohd F. Animal Model of Gestational Diabetes Mellitus with Pathophysiological Resemblance to the Human Condition Induced by Multiple Factors (Nutritional, Pharmacological, and Stress) in Rats. BioMed Research International Volume. 2016;1-14. http:// dx.doi.org/10.1155/2016/9704607

25. Maricelma da Silva SS, Yuri KS, Paula HOL, Iracema MPC, Marilza VCR, De'bora CD. Oxidative stress status and lipid profiles of diabetic pregnant rats exposed to cigarette smoke. Reproductive BioMedicine. 2010. 20: 547- 552 26. Guneli, E. K. Tugyan, H. Ozturk, M. Gumustekin, S. Cilaker, N. Uysal Effect of Melatonin on Testicular Damage in Streptozotocin-Induced Diabetes Rats. EurSurg Res. 2008; 40:354-360 PubMed . DOI: 10.1159/000118032

27. Rammohan S, Mohd. Zaini A, Amirin S. Effect of ethanolic extract of andrographis Paniculata (burm. F.) Nees on a combination of Fat-fed diet and low dose streptozotocin induced chronic insulin resistance in rats. Diabetologia croatica. 2008: 37-41

28. Antonios C, Antonios H, Konstantinos K and Elli K. The use of animal models in the study of diabetes mellitus. In vivo. 2009. 23: 245-258.

29. Adeniji, AA Lawal, SK, Osinubi, AAA, Kusemiju T, Uyaiabasi NG. The comparative effects of metformin and insulin on the kidney, lung and heart of streptozotocin-induced diabetic female Wistar rats, Nigerian. Quartery Journal of Hospital Medicine. 2016 26(1): 353-359. ISSN: 0189-2657

30. World Health Organisation. Diagnostic criteria and classification of hyperglycaemia first detected in pregnancy Geneva: WHO; 2013 [cited 2016 01/11]. Available from: http:/ /apps.who.int/iris/bitstream/10665/85975/1/ WHO_NMH_MND_13.2_eng.pdf?ua=1

31. Veeraswamy S, Vijayam, B, Gupta VK. and Kapur A. The Public Health Relevance and Approach. Diabetes Research and Clinical Practice. 2012. 97, 350-358. http://dx. doi.org/10.1016/j.diabres.2012.04.024

32. Crowther CA, Hiller JE, Moss JR, McPhee AJ, Jeffries WS, Robinson JS, Australian Carbohydrate Intolerance 
Study in Pregnant Women (ACHOIS) Trial Group. Effect of treatment of gestational diabetes mellitus on pregnancy outcomes. N Engl J Med. 2005;352(24):2477-86.

33. Landon MB, Spong CY, Thom E, Carpenter MW, Ramin SM, Casey B, et al. A multicenter, randomized trial of treatment for mild gestational diabetes. $N$ Engl J Med. 2009;361(14):1339-48.

34. Rotheram-Borus, MJ, Tomlinson M, Swendeman D, Lee A. and Jones E. Standardized Functions for Smartphone Applications: Examples from Maternal and Child Health. International Journal of Telemedicine Applications. 2012: 1: 21-21

35. Langer O, Conway DL, Berkus MD, Xenakis EMJ. and Gonzales O. A Comparison of Glyburide and Insulin in Women with Gestational Diabetes Mellitus. New England Journal of Medicine. 2000; 343:1134-1138.

36. Jovanovic L, Pettitt DJ. Gestational diabetes mellitus. JAMA. 2001; 286:2516-2518 PubMed

37. Odiba JO, and Mabhala MA. The Effectiveness of Glyburide Compared to Insulin in the Management of Gestational Diabetes Mellitus: A Systematic Review. Journal of Diabetes Mellitus. 2015; 5:58-66. http://dx.doi. org/10.4236/jdm.2015.52007

38. Yasushi T, Naohiko T, Satoru N, Shotaro S, Hidekazu K, Akira F, Kouhei A, Kunio Yufu, Mikiko N, Tetsunori Saikawa. Production of Reactive Oxygen Species in the Diabetic Heart-Roles of Mitochondria and NADPH Oxidase -Circ J. 2014; 78: 300-306.

39. Asmat U, Abad K, Ismail K. Diabetes mellitus and oxidative stress-A concise. Review. Saudi Pharmacentical Journal. 2016; 24:547-553 PubMed .

40. Selim F, Wael A, and Keith E. Jackson. Diabetes-Induced Reactive Oxygen Species. Mechanism of Their Generation and Role in Renal Injury. Journal of Diabetes Research. 2017; 1-30.https://doi.org/10.1155/2017/8379327

41. Lenzen S, Drinkgern J, Tiedge M. Low antioxidant enzyme gene expression in pancreatic islets compared with various other mouse tissues. Free Radic Biol Med. 1996; 20:463-366 PubMed . [PubMed:8720919]

42. Tiedge M, Lortz S, Drinkgern J, Lenzen S. Relationship between antioxidant enzyme gene expression and antioxidant defense status of insulin-producing cells. Diabetes. 1997; 46:1733-1742 PubMed . [PubMed: 9356019] 43. Maechler P, Jornot L, Wollheim CB. Hydrogen peroxide alters mitochondrial activation and insulin secretion in pancreatic beta cells. J Biol Chem. 1999; 274:27905-27913 PubMed . [PubMed:10488138]
44. Sakai K, Matsumoto K, Nishikawa T, Suefuji M, Nakamaru K, Hirashima Y, Kawashima J, Shirotani T, et al. Mitochondrial reactive oxygen species reduce insulin secretion by pancreatic islet $\beta$-cells. Biochem Biophys Res Comm. 2003; 300:216-222. (PubMed: 12480546)

45. Kaneto H, Xu G, Fujii N, Kim S, Bonner-Weir S, Weir GC. Involvement of c-Jun N-terminal kinase in oxidative stress-mediated suppression of insulin gene expression. J Biol Chem. 2002; 277:30010-30018 PubMed . [PubMed: 12011047]

46. Kaneto H, Xu G, Song KH, Suzuma K, Bonner-Weir S, Sharma A, Weir GC. Activation of the hexosamine pathway leads to deterioration of pancreatic beta-cell function through the induction of oxidative stress. J Biol Chem. 2001; 276:31099-31104 PubMed . [PubMed:11390407] 47. Jonas JC, Laybutt DR, Steil GM, Trivedi N, Pertusa JG, Van de Casteele M, Weir GC, Henquin JC. High glucose stimulates early response gene c-Myc expression in rat pancreatic beta cells. J Biol Chem. 2001; 276:3537535381 PubMed . [PubMed: 11457846]

48. Jonas JC, Sharma A, Hasenkamp W, Ilkova H, Patane G, Laybutt R, Bonner-Weir S, Weir GC. Chronic hyperglycemia triggers loss of pancreatic beta cell differentiation in an animal model of diabetes. J Biol Chem. 1999; 274:14112-14121 PubMed . [PubMed: 10318828]

49. Efanova IB, Zaitsev SV, Zhivotovsky B, Kohler M, Efendic S, Orrenius S, Berggren PO. Glucose and tolbutamide induce apopotosis in pancreatic B-cells. J Biol Chem. 1998; 273:22501-22507 PubMed .

50. Moran A, Zhang HJ, Olsonm LK, Harmon JS, Poitoust V, Robertson RP. Differentiation of glucose toxicity from $\beta$-cell exhaustion during the evolution of defective insulin gene expression in the pancreatic islet cell line, HIT-T15. J Clin Invest. 2000; 99:534-539 PubMed . [PubMed: 9022089]

51. Donath MY, Gross DJ, Cerasi E, Kaiser N. Hyperglycemia-induced $B$-cell apoptosis in pancreatic islets of Psammomys obesus during development of diabetes. $\mathrm{Di}$ abetes. 1999; 48:738-744 PubMed . [PubMed: 10102689] 52. Owens DR. Clinical Evidence for the Earlier Initiation of Insulin Therapy in Type 2 Diabetes. Diabetes Technology \& Therapentics. (2013);15 (9);776-785. DOI: 10.1089/ dia.2013.0081

53. Zhao LP, Sheng XY, Zhou S, Yang T, Ma LY, Zhou $Y$, et al. Metformin versus insulin for gestational diabetes mellitus: A meta-analysis. Br J Clin Pharmacol. 2015; 80(5): 1224 PubMed -34. 
54. Bonaventure CO, Theophine CO, Victor EO, Christiana NI, and Edwin OA. Comparative Study of the Antioxidant Effects of Metformin, Glibenclamide, and Repaglinide in Alloxan-Induced Diabetic Rats. Journal of Diabetes Research. 2016; 1-5.http://dx.doi. org/10.1155/2016/1635361

55. Alaa AAA and Imad AJ. Thanoon. Comparative Effects of Glibenclamide and Metformin on C-Reactive Protein and Oxidant/Antioxidant Status in Patients with Type II Diabetes Mellitus. SQU Med J. 2012;12(1): 55 PubMed -61

56. Holden SE, Jenkins-Jones S, Currie CJ. Association between Insulin Monotherapy versus Insulin plus Metformin and the Risk of All- Cause Mortality and Other Serious Outcomes: A Retrospective Cohort Study. PLoS One. 2016; 11(5): PubMed e0153594. doi:10.1371/journal.pone.0153594

57. Balsells M, Garcia-Patterson A, Sola I, Roque M, Gich I, Corcoy R. Glibenclamide, metformin, and insulin for the treatment of gestational diabetes: a systematic review and meta-analysis. BMJ. 2015;350:h102.

58. Wirth A. Anti-diabetic drugs. Weight reduction as a favourable side effect. Internist (Berl). 2011; 52: 451. https:// doi.org/10.1007/s00108-011-2811-x

59. Mansour A, Abbas N, Sirous A, Ahmad D, Mohammad O, Ayub G, Ardeshir M. Investigation and comparison of the effect of saffron petals hydroalcoholic extract with metformin and glibenclamide on serum glucose, HbA1c and insulin levels in streptozotocin-induced diabetic rats, J Res Med Dent Sci, 2018; 6 (5):20-24

60. Atsuo T, Akiko M-Y, Ryosuke N, Yuka S, Masayuki S. Hypoglycaemic Effects of Antidiabetic Drugs in Streptozotocin-Nicotinamide-Induced Mildly Diabetic and Streptozotocin-Induced Severely Diabetic Rats Basic \& Clinical Pharmacology \& Toxicology, 2008; 103, 560-568. 61. Kefas BA, Cai Y, Kerckhofs K, Ling Z, Martens G, Heimberg $\mathrm{H}$, et al. Metformin induced stimulation of AMP-activated protein kinase in beta-cells impairs their glucoseresponsiveness and can lead to apoptosis. Biochem Pharmacol. 2004; 68(3): 409-16.

62. Leclerc I, Woltersdorf WW, Xavier GDS, Rowe RL, Cross SE, Korbutt GS, et al. Metformin, but not leptin, regulates AMP-activated protein kinase in pancreatic islets: impact on glucose-stimulated insulin secretion. Am J Physiol Endocrinol Metab. 2004; 286 E1023-E31.

63. Gregg B, Elghazi L, Alejandro EU, Smith MR, Blandino-RosanoM, El-Gabri D, et al. Exposure of mouse em- bryonic pancreas to metformin enhances the number of pancreaticprogenitors. Diabetologia. 2014;57 (12):2566-75. 64. Jiang Y, Huang W, Wang J, Xu Z, He J, Lin X, et al. Metformin plays a dual role inMIN6 pancreatic beta cell function through AMPK-dependent autophagy. Int J Biol Sci. 2014; 10(3):268-77.

65. Masini M, Anello M, Bugliani M, Marselli L, Filipponi F, Boggi U, et al. Prevention by metformin of alterations induced by chronic exposure to high glucose in human islet beta cells is associated with preserved ATP/ADP ratio. Diabetes Res Clin Pract. 2014; 104(1):163-70.

66. Nguyen L, Shiao-Yng C, Adrian Kee KT. Metformin from mother to unborn child -Are there unwarranted effects? EBio Medicine. 2018; 35:394-404

67. Denno KM, Sadler TW. Effects of Biguanide Class of Oral Hypoglycemic Agents on Mouse Embryogenesis. Teratology. 1994; 49:260-6.

68. Ullah I, Ullah N, Naseer MI, Lee HY, Kim MO. Neuroprotection with metformin and thymoquinone against ethanol-induced apoptotic neurodegeneration in prenatal ratcortical neurons. BMC Neurosci. 2012; 13:11.

69. Wu Y,Wang F, Mao F, Wang C, QuonMJ, Yang P. Cellular stress, Excessive Apoptosis, and the effect of Metformin in aMouse Model of Type 2 Diabetic Embryophathy. Diabetes. 2015; 64:2526-36.

70. Langer O. When diet fails: insulin and oral hypoglycemic agents as alternatives for the management of gestational diabetes mellitus. J Matern Fetal Neonatal Med. 2002; 11(4):218-25. [PubMed: 12375674]

71. Robert S. Lindsay \& Mary R. Loeken. Metformin use in pregnancy: promises and uncertainties Diabetologia. 2017; 60:1612-1619. DOI 10.1007/s00125-017-4351-y

72. Joanne EG, Maria L, Ester G, Marie-Claude A, Marian B, Bénédicte B-N, Miriam G, Kari K, Nathalie L, Margery M, Amanda JN, Anna P, Anke R, Helen D. Metformin exposure in first trimester of pregnancy and risk of all or specific congenital anomalies: exploratory case-control study. BMJ. 2018;361:k2477 http://dx.doi.org/10.1136/ bmj.k2477

73. Elliott BD, Langer O, Schuessling F. Human placental glucose uptake and transport are not altered by the oral antihyperglycemic agent metformin. Am J Obstet Gynecol. 1997; 176(3):527-30. [PubMed: 9077600]

74. Spaulonci CP, Bernardes LS, Trindade TC, et al. Randomized trial of metformin vs insulin in the management of gestational diabetes. Am J Obstet Gynecol. 2013; 209(1):34, e1-7. [PubMed: 23524173]. 
75. Silva JC, Fachin DR, Coral ML, et al. Perinatal impact of the use of metformin and glyburide for the treatment of gestational diabetes mellitus. J Perinat Med. 2012; 40(3):225-8. [PubMed: 22505499]

76. Rowan JA, Hague WM, Gao W, Battin MR, Moore MP. Metformin versus insulin for the treatment of gestational diabetes. N Engl J Med. 2008; 358:2003-2015.

77. Thompson CS, Strong P, Mikhailidis DP. Improve- ment of ketoacidosis in the diabetic rat after the administration of the oral antilipolytic agent GR 79236. Clinical Science. 1994; 86, 593-598. PMID: 8033512

78. Qinna Nidal A and Badwan Adnan A. Impact of streptozotocin on altering normal glucose homeostasis during insulin testing in diabetic rats compared to normoglycemic rats. Drug Design, Development and Therapy. 2015:9 2515-2525. 